\title{
Co-expression of aFGF and FGFR-1 is predictive of a poor prognosis in patients with esophageal squamous cell carcinoma
}

\author{
KOICHI SUGIURA, SOJI OZAWA ${ }^{1}$, YUKO KITAGAWA, MASAKAZU UEDA and MASAKI KITAJIMA \\ Department of Surgery, School of Medicine, Keio University, 35 Shinanomachi, Shinjuku-ku, Tokyo 160-8582, Japan
}

Received October 18, 2006; Accepted November 22, 2006

\begin{abstract}
Overexpression of aFGF, bFGF and FGFR-1 has been reported in various cancers, and it has been suggested that it may be a poor prognostic factor in cases with solid tumors. Therefore, we attempted to determine whether overexpression of aFGF, bFGF and FGFR-1 might also be a poor prognostic factor in patients with esophageal squamous cell carcinoma, and examined the expression of aFGF, bFGF and FGFR-1 in esophageal cancer tissue specimens to clarify their clinical significance. Seventy-nine patients with squamous cell carcinoma of the esophagus who underwent resection at the Department of Surgery, Keio University Hospital, were enrolled as the subjects of this study. None of the patients had received any previous treatment. Formalin-fixed and paraffin-embedded sections of esophageal cancer tissue were stained by immunohistochemical methods and examined for expression of the angiogenetic factors and their receptors, and also to determine the microvascular density (MVD). We examined the correlations between the expression of aFGF, bFGF and FGFR-1, and the MVD, clinicopathological background factors and survival of the patients by conducting statistical analyses of the data. The results revealed that positive aFGF expression was associated with a larger tumor area $(\mathrm{p}=0.009)$, and co-expression of both aFGF and FGFR-1 was associated with a larger tumor area $(\mathrm{p}=0.01)$ and poorer prognosis $(\mathrm{p}=0.04)$. There were positive correlations between the expression of aFGF and FGFR-1 ( $<<0.0001)$, and between those of bFGF and FGFR-1 ( $\mathrm{p}=0.04)$. aFGF may promote proliferation of esophageal cancer cells in an angiogenesisindependent and autocrine manner, and may contribute to rapid growth of esophageal cancer on recurrence after esophageal resection.
\end{abstract}

Correspondence to: Dr Soji Ozawa, ${ }^{1}$ Present address: Department of Surgery, School of Medicine, Fujita Health University, Ban Buntane Houtokukai Hospital, 3-6-10 Otobashi, Nakagawa-ku, Nagoya 454-8509, Japan

E-mail: sozawa@fujita-hu.ac.jp

Key words: angiogenesis, esophageal carcinoma, fibroblast growth factor-1, fibroblast growth factor-2, fibroblast growth factor receptor-1

\section{Introduction}

The current staging of esophageal cancer is based on the UICC (International Union Against Cancer) TNM classification, and the surgical pathological findings have proven to be valuable (1). The $\mathrm{pN}$ factor is presently considered to be the most useful predictor of outcome in cases of squamous cell carcinoma of the esophagus, and 5-year survival rates of 61$80 \%$ and $34-45 \%$ have been reported for the pN0 status and pN1 status, respectively $(2,3)$. Although there is clear evidence that patients with early-stage esophageal cancer do relatively well when treated by surgical resection alone, we have sometimes encountered even earlier-stage cancer patients who have developed recurrent disease and died after a curative resection; recurrence rates of $15 \%$ in cases with $\mathrm{pN} 0$ esophageal cancer and $14 \%$ in cases with pStage I disease have been reported (4). These observations suggest that the TNM classification alone may not be sufficient for accurate prediction of the prognosis in esophageal cancer patients, and new indicators of the biological malignant potential of squamous cell carcinoma of the esophagus must be explored (5).

It has been reported that cancer development depends on a variety of physiological processes, such as carcinogenesis at the cell oncogene level, proliferation, and tumor growth and progression. Tumor angiogenesis, as the means of supply of oxygen and nutrients, is necessary for tumor growth, and also for tumor progression, because it increases the opportunity for the tumor cells to enter the circulation (6). It has been demonstrated that the greater the number of tumor vessels, the greater the opportunity for tumor cells to enter the circulation (7), and that newly formed capillaries are more easily penetrated than mature vessels (8). Thus, the relationship between tumor angiogenesis and tumor growth has already been demonstrated, and a new advanced anti-tumor angiogenesis strategy has been attempted for cancer therapy (9-10).

As angiogenetic factors are secreted from cancer cells, the expression levels of VEGF, aFGF (acidic FGF; FGF-1) and bFGF (basic FGF; FGF-2) in cancers of various organs were investigated, and their correlations with the MVD (microvascular density) were examined. The expression levels of the VEGF, aFGF and bFGF receptors in various cancers were also reported. The FGF family consists of 10 members (FGF-1-10) and 4 FGF-homologous factors, and comprises a group of proteins with related functions (11-13). These polypeptides have been shown to act as mitogens for 
numerous cell types derived from the mesoderm and neurectoderm, and also for cancer cells (14-16). FGFs are well known as not only endothelial growth factors, but also as angiogenesis inducing factors. They act through high-affinity binding sites that mediate biological activity via a group of tyrosine kinase membrane receptors from the FGFR family. The FGFRs are encoded by at least 4 kinds of genes and possess immunoglobulin-like extracellular domains (17).

Overexpression of aFGF, bFGF and FGFR-1 in various cancers has been reported, and it has been suggested that it may be a poor prognostic factor in cases with solid tumors, including breast cancer (18-19), glioblastoma (20), hepatocellular carcinoma $(21,22)$, and pancreatic carcinoma (23). Furthermore, numerous studies have suggested that proliferation of cancer cells might be promoted in an autocrine manner, based on the observation of a correlation between aFGF and FGFR-1 expression in breast cancer (19), and between bFGF and FGFR-1 in hepatocellular carcinoma (21).

Based on these previous observations, it was expected that overexpression of aFGF, bFGF and FGFR-1 might represent a prognostic factor in patients with esophageal squamous cell carcinoma, and we examined the expression of aFGF, bFGF and FGFR-1 in resected specimens of esophageal squamous cell carcinoma and their clinical significance, and also clarified the correlation between the expression levels of aFGF and FGFR-1, and those of bFGF and FGFR-1 in esophageal squamous cell carcinoma. Our results suggested that the cancer cell proliferation in esophageal squamous cell carcinoma might be promoted in an autocrine manner.

\section{Materials and methods}

Clinical materials. Seventy-nine patients with esophageal squamous cell carcinoma who had no history of previous treatment and underwent esophagectomy at Keio University Hospital (Tokyo, Japan) between January 1990 and December 1993 were enrolled for the study. Of the 79 patients, 68 were male and the remaining 11 were female. The patients ranged in age from 36 to 83 years, and their average age was 61.5 years. The pathological examinations were performed according to the Guidelines for Clinical and Pathological Studies on Carcinoma of the Esophagus of the Japanese Society for Esophageal Diseases (24). Based on the above, category pT1b $(n=22)$ corresponds to tumors that have invaded the submucosa, category pT2 $(n=13)$ corresponds to tumors that have invaded the muscularis propria, category pT3 $(n=44)$ corresponds to tumors that have invaded the adventitia, category pN0 $(n=28)$ corresponds to tumors with no regional lymph node metastasis, and category $\mathrm{pN} 1(\mathrm{n}=51)$ corresponds to tumors with regional lymph node metastasis. Patients were followed-up at the outpatient clinic, and diagnostic examinations consisting of chest X-ray, chest and abdominal computed tomography, and abdominal ultrasonography were performed every 6 months to detect recurrences. The maximum patient follow-up period was 147 months, and the mean observation period was 46 months.

Immunohistochemical staining. Ten- $\mu \mathrm{m}$ sections were made from $10 \%$-formalin-fixed, paraffin-embedded blocks and mounted on slides. The blocks were selected from the most invasive area of the carcinoma according to the pathology report. Sections were deparaffinized and rehydrated and then digested in $1 \%$ trypsin in calcium chloride for $30 \mathrm{~min}$ at $37^{\circ} \mathrm{C}$. The tissue sections were covered with $3 \% \mathrm{H}_{2} \mathrm{O}_{2}$ in methanol for $5 \mathrm{~min}$ and incubated for $60 \mathrm{~min}$ in bovine serum albumin (BSA) to suppress nonspecific IgG binding. The sections were then incubated with a 1:100 dilution of the primary antibody (aFGF, bFGF and FGFR-1), and a 1:200 dilution of the antibody for von Willebrand factor (primary antibody used for measurement of the MVD) in phosphatebuffered saline (PBS) at $4^{\circ} \mathrm{C}$ for $24 \mathrm{~h}$. A labeling streptavidin biotin (LSAB) kit (Dako, Glostrup, Denmark) was used for immunohistochemical staining. Diamino benzidine tetrahydrochloride (DAB) was used as the chromogen, and the sections were counterstained with Meyer's hematoxylin.

Antibodies. The primary antibodies were monoclonal antibovine aFGF antibody (Upstate Biotechnology Inc., USA), monoclonal anti-bovine bFGF antibody (Upstate Biotechnology Inc.), monoclonal anti-human FGFR-1 antibody (Santa Cruz Inc., USA), and polyclonal antihuman von Willebrand factor antibody (Dako) for the MVD analysis.

Staining analysis. The staining areas with the monoclonal antibodies for FGF, bFGF and FGFR-1 tended to be either $<30 \%$ or $>80 \%$. If the cytoplasm of the cancer cells were stained $>30 \%$ (aFGF and FGFR-1) or $>80 \%$ (bFGF), we judged the staining as 'positive' (5). We defined MVD as the count of microvasculars per square-millimeter in the 'vascular hot spot' in the deepest cancer sections. Cases with a calculated density of more than $60 / \mathrm{mm}^{2}$ were considered to have a high MVD (5).

Statistical analysis. The $\chi^{2}$ test was used to evaluate the differences in the background factors among the patient groups. The cumulative survival rates for the patient groups were calculated by the Kaplan-Meier method, and compared using the log rank test. The influence of each variable on the patients' survival was assessed by the Cox proportionalhazards regression model. Statistical significance was defined as $\mathrm{p}<0.05$. We used StatView for Windows, Version 5.0 (SAS Institute Inc.), for all the analyses.

\section{Results}

According to the results of immunohistochemical staining, aFGF and bFGF were expressed mainly in the cytoplasm and perinuclear areas of the cancer cells and the stromal fibroblasts, and FGFR-1 was expressed mainly in the cytoplasm of the cancer cells and stromal fibroblasts (Fig. 1). The expression of all of the three molecules, aFGF, bFGF and FGFR-1, was relatively weak in the endothelial cells.

Forty-seven (59\%) of the 79 cases were evaluated as aFGFpositive, 43 (54\%) as bFGF-positive, and 47 (59\%) as FGFR1-positive.

Thirty-five (44\%) as both aFGF- and FGFR-1-positive, and $22(28 \%)$ as both aFGF- and FGFR-1-negative. Twentysix $(33 \%)$ were evaluated as both bFGF- and FGFR-1positive, and 18 (23\%) as both- bFGF and FGFR-1-negative. 
aFGF
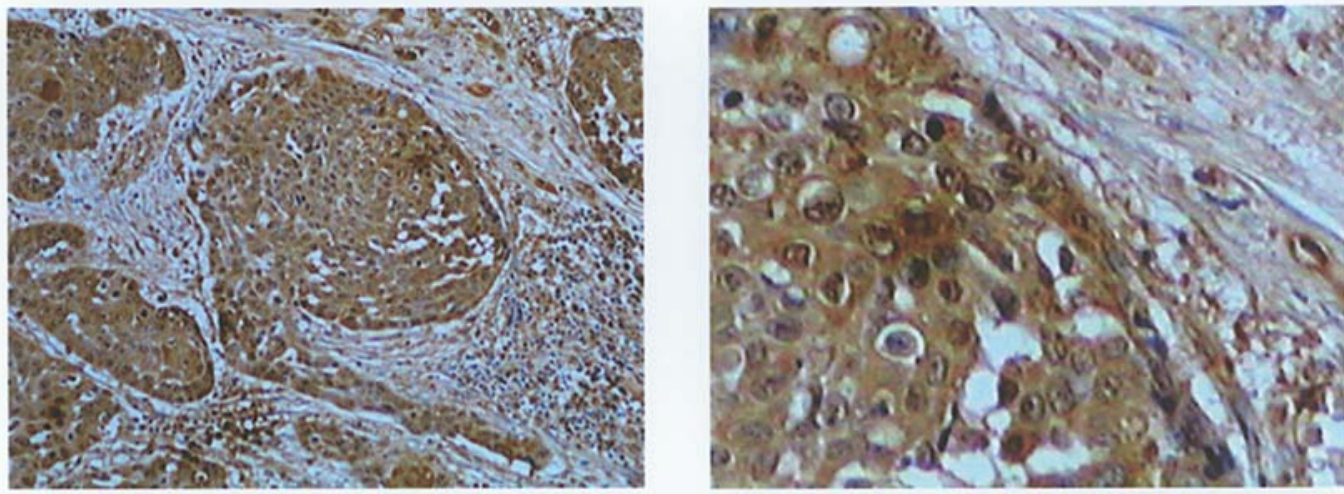

bFGF
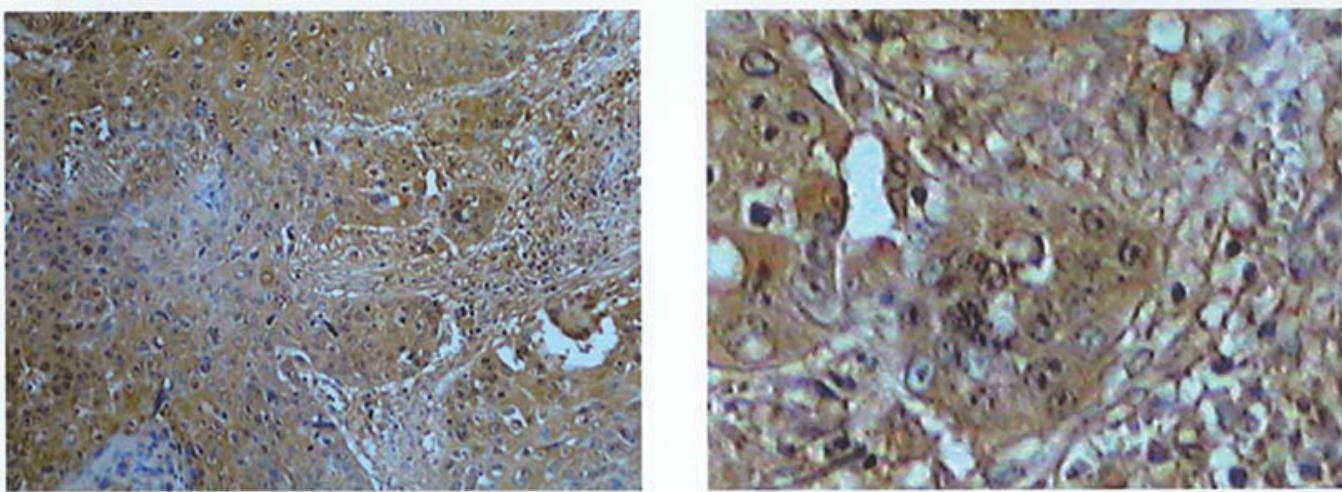

FGFR-1
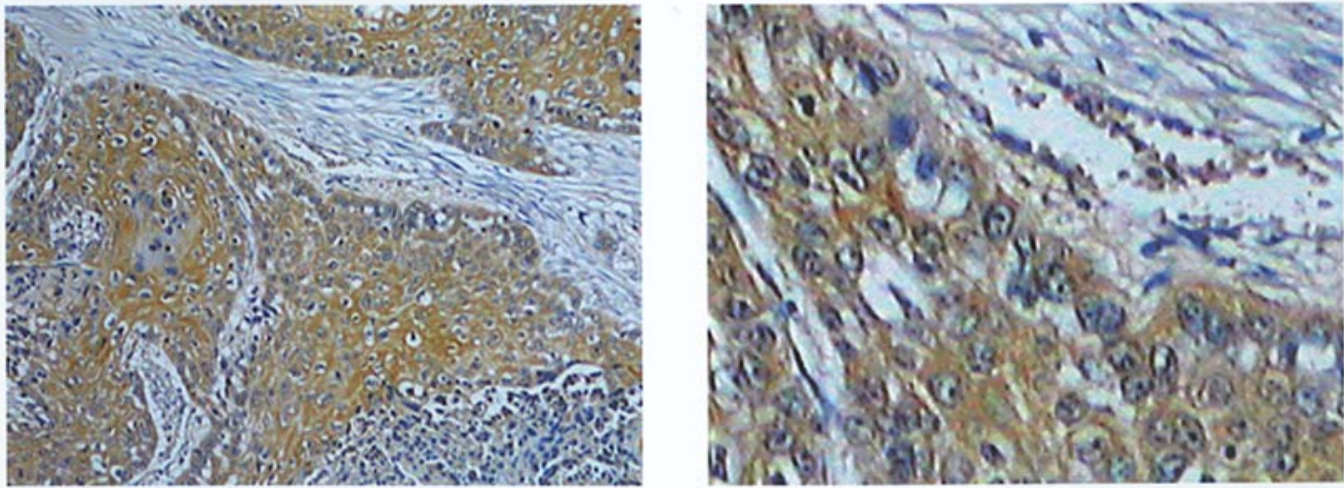

Figure 1. Immunohistochemical staining. The expression of aFGF and bFGF was identified mainly in both the cytoplasm and perinuclear areas of the cancer cells, and stromal fibroblasts. The expression of FGFR-1 was identified mainly in the cytoplasm of the cancer cells and stromal fibroblasts.

The patients were divided into groups, as follows, based on the above findings: an aFGF-positive group and aFGFnegative group; a bFGF-positive group and bFGF-negative group; a FGFR-1-positive group and FGFR-1-negative group; a aFGF- and FGFR-1-positive group and an aFGFand FGFR-1-negative group; a bFGF- and FGFR-1-positive group and a bFGF- and FGFR-1-negative group. The following clinicopathological background factors were compared in each of the paired groups: age, sex, location of the tumor, operative approach (RTTE or THE), postoperative therapy (chemotherapy or radiation), tumor depth, differentiation, infiltration, lymphatic invasion, venous invasion, intraepidermal expansion, intramural metastasis, lymph node metastasis, pathological stage, MVD, tumor area [calculated as the longest axis (mm) multiplied by the shortest axis (mm) on the tumor surface] and number of lymph node metastases (Table I). There were no significant differences in the clinical background factors between any of the two groups. The aFGF-positive group had a larger tumor area than the aFGFnegative group $(\mathrm{p}=0.009)$. The aFGF- and FGFR-1-positive group also had a larger tumor area than the aFGF- and FGFR-1-negative group $(\mathrm{p}=0.01)$.

The correlations between the expression of aFGF and that of FGFR-1, and between the expression of bFGF and that of FGFR-1 were analyzed (Table II). There were positive correlations between the expression of aFGF and that of 
Table I. Clinicopathological backgrounds.

\begin{tabular}{|c|c|c|c|c|c|c|c|c|c|c|}
\hline Factors & $\begin{array}{c}\text { aFGF } \\
\text { positive } \\
(n=47 / 79)\end{array}$ & p-value & $\begin{array}{c}\text { bFGF } \\
\text { positive } \\
(n=43 / 79)\end{array}$ & p-value & $\begin{array}{c}\text { FGFR-1 } \\
\text { positive } \\
(n=47 / 79)\end{array}$ & p-value & $\begin{array}{c}\text { aFGF+FGFR-1 } \\
\text { positive } \\
(\mathrm{n}=35 / 57)\end{array}$ & p-value & $\begin{array}{c}\text { bFGF+FGFR-1 } \\
\text { positive } \\
(n=26 / 44)\end{array}$ & p-value \\
\hline \multicolumn{11}{|l|}{ Age } \\
\hline-49 & $8 / 11$ & \multirow[t]{4}{*}{ N.S. } & $7 / 11$ & \multirow[t]{4}{*}{ N.S. } & $9 / 11$ & \multirow[t]{4}{*}{ N.S. } & $6 / 7$ & \multirow[t]{4}{*}{ N.S. } & $6 / 8$ & \multirow[t]{4}{*}{ N.S. } \\
\hline $50-59$ & $13 / 24$ & & $17 / 24$ & & $12 / 24$ & & $8 / 15$ & & $8 / 12$ & \\
\hline $60-69$ & $11 / 21$ & & $10 / 21$ & & $11 / 21$ & & $8 / 16$ & & $4 / 8$ & \\
\hline 70- & $15 / 23$ & & $9 / 23$ & & $15 / 23$ & & $13 / 19$ & & $8 / 16$ & \\
\hline \multicolumn{11}{|l|}{ Sex } \\
\hline Male & $40 / 68$ & \multirow[t]{2}{*}{ N.S. } & $37 / 68$ & \multirow[t]{2}{*}{ N.S. } & $43 / 68$ & \multirow[t]{2}{*}{ N.S. } & $31 / 49$ & \multirow[t]{2}{*}{ N.S. } & $23 / 37$ & \multirow[t]{2}{*}{ N.S. } \\
\hline Female & $7 / 11$ & & $6 / 11$ & & $4 / 11$ & & $4 / 8$ & & $3 / 7$ & \\
\hline \multicolumn{11}{|l|}{ Location } \\
\hline Upper & $8 / 11$ & \multirow[t]{3}{*}{ N.S. } & $8 / 11$ & \multirow[t]{3}{*}{ N.S. } & $9 / 11$ & \multirow[t]{3}{*}{ N.S. } & $7 / 8$ & \multirow[t]{3}{*}{ N.S. } & $7 / 8$ & \multirow[t]{3}{*}{ N.S. } \\
\hline Middle & $28 / 46$ & & $26 / 46$ & & $26 / 46$ & & $21 / 35$ & & $15 / 26$ & \\
\hline Lower & $11 / 22$ & & $9 / 22$ & & $12 / 22$ & & $7 / 14$ & & $4 / 10$ & \\
\hline \multicolumn{11}{|l|}{ Operation } \\
\hline RTTE & $36 / 60$ & \multirow[t]{2}{*}{ N.S. } & $35 / 60$ & \multirow[t]{2}{*}{ N.S. } & $37 / 60$ & N.S. & $26 / 41$ & N.S. & $21 / 32$ & N.S. \\
\hline THE & $11 / 19$ & & $8 / 19$ & & $10 / 19$ & & $9 / 16$ & & $5 / 12$ & \\
\hline Adjuvant $\mathrm{C}$ & & & & & & & & & & \\
\hline$(-)$ & $36 / 57$ & N.S. & $31 / 57$ & N.S. & $34 / 57$ & N.S. & $27 / 43$ & N.S. & $19 / 33$ & N.S. \\
\hline$(+)$ & $11 / 22$ & & $12 / 22$ & & $13 / 22$ & & $8 / 14$ & & $7 / 11$ & \\
\hline Tumor dept & & & & & & & & & & \\
\hline $\mathrm{pT} 1 \mathrm{~b}$ & $11 / 22$ & N.S. & $11 / 22$ & N.S. & $11 / 22$ & N.S. & $9 / 18$ & N.S. & $7 / 15$ & N.S. \\
\hline pT2 & $6 / 13$ & & $7 / 13$ & & $8 / 13$ & & $5 / 9$ & & $4 / 7$ & \\
\hline pT3 & $30 / 44$ & & $25 / 44$ & & $28 / 44$ & & $21 / 30$ & & $15 / 22$ & \\
\hline Differentiat & & & & & & & & & & \\
\hline Well & $8 / 14$ & N.S. & $7 / 14$ & N.S. & $8 / 14$ & N.S. & $7 / 12$ & N.S. & $5 / 9$ & N.S. \\
\hline Moderate & $37 / 61$ & & $34 / 61$ & & $37 / 61$ & & $28 / 44$ & & $21 / 33$ & \\
\hline Poor & $2 / 4$ & & $2 / 4$ & & $2 / 4$ & & $0 / 1$ & & $0 / 2$ & \\
\hline Infiltration & & & & & & & & & & \\
\hline$\alpha$ & $9 / 17$ & N.S. & $7 / 17$ & N.S. & $7 / 17$ & N.S. & $6 / 14$ & N.S. & $4 / 12$ & N.S. \\
\hline B & $31 / 51$ & & $29 / 51$ & & $32 / 51$ & & $23 / 35$ & & $19 / 29$ & \\
\hline$\gamma$ & $7 / 11$ & & $7 / 11$ & & $8 / 11$ & & $6 / 8$ & & $3 / 3$ & \\
\hline Lymphatic & & & & & & & & & & \\
\hline$(-)$ & $7 / 14$ & N.S. & $4 / 14$ & N.S. & $6 / 14$ & N.S. & $5 / 12$ & N.S. & $3 / 10$ & N.S. \\
\hline$(+)$ & $40 / 65$ & & $39 / 65$ & & $41 / 65$ & & $30 / 45$ & & $23 / 34$ & \\
\hline Venous inv & & & & & & & & & & \\
\hline$(-)$ & $34 / 59$ & N.S. & $36 / 59$ & N.S. & $36 / 59$ & N.S. & $26 / 43$ & N.S. & $22 / 34$ & N.S. \\
\hline$(+)$ & $13 / 20$ & & $7 / 20$ & & $11 / 20$ & & $9 / 14$ & & $4 / 10$ & \\
\hline Intraepidern & & & & & & & & & & \\
\hline$(-)$ & $25 / 40$ & N.S. & $25 / 40$ & N.S. & $27 / 40$ & N.S. & $19 / 29$ & N.S. & $14 / 20$ & N.S. \\
\hline$(+)$ & $22 / 39$ & & $18 / 39$ & & $20 / 39$ & & $16 / 28$ & & $12 / 24$ & \\
\hline Intramural $\mathrm{r}$ & & & & & & & & & & \\
\hline$(-)$ & $40 / 70$ & N.S. & $37 / 70$ & N.S. & $42 / 70$ & N.S. & $29 / 48$ & N.S. & $22 / 38$ & N.S. \\
\hline$(+)$ & $7 / 9$ & & $6 / 9$ & & $5 / 9$ & & $6 / 9$ & & $4 / 6$ & \\
\hline Lymph nod & & & & & & & & & & \\
\hline$(-)$ & $14 / 28$ & N.S. & $12 / 28$ & N.S. & $15 / 28$ & N.S. & $12 / 24$ & N.S. & $7 / 16$ & N.S. \\
\hline$(+)$ & $33 / 51$ & & $31 / 51$ & & $32 / 51$ & & $23 / 33$ & & $19 / 28$ & \\
\hline
\end{tabular}


Table I. Continued.

\begin{tabular}{|c|c|c|c|c|c|c|c|c|c|c|}
\hline Factors & $\begin{array}{c}\text { aFGF } \\
\text { positive } \\
(\mathrm{n}=47 / 79)\end{array}$ & p-value & $\begin{array}{c}\text { bFGF } \\
\text { positive } \\
(n=43 / 79)\end{array}$ & p-value & $\begin{array}{l}\text { FGFR-1 } \\
\text { positive } \\
(n=47 / 79)\end{array}$ & p-value & $\begin{array}{c}\text { aFGF+FGFR-1 } \\
\text { positive } \\
(\mathrm{n}=35 / 57)\end{array}$ & $\mathrm{p}$-value & $\begin{array}{c}\text { bFGF+FGFR-1 } \\
\text { positive } \\
(n=26 / 44)\end{array}$ & p-value \\
\hline \multicolumn{11}{|l|}{ Pathological stage } \\
\hline I & $6 / 14$ & N.S. & $6 / 14$ & N.S. & $6 / 14$ & N.S. & $5 / 12$ & N.S. & $3 / 9$ & N.S. \\
\hline IIA & $7 / 14$ & & $6 / 14$ & & $9 / 14$ & & $7 / 12$ & & $4 / 7$ & \\
\hline IIB & $12 / 18$ & & $13 / 18$ & & $12 / 18$ & & $9 / 13$ & & $7 / 10$ & \\
\hline III & $13 / 19$ & & $14 / 19$ & & $14 / 19$ & & $10 / 12$ & & $9 / 11$ & \\
\hline IV & $9 / 14$ & & $8 / 14$ & & $6 / 14$ & & $4 / 8$ & & $3 / 7$ & \\
\hline \multicolumn{11}{|l|}{ MVD } \\
\hline Low & $30 / 54$ & N.S. & $27 / 53$ & N.S. & $34 / 54$ & N.S. & $33 / 53$ & N.S. & $40 / 66$ & N.S. \\
\hline High & $15 / 25$ & & $14 / 26$ & & $15 / 25$ & & $16 / 26$ & & $10 / 13$ & \\
\hline Tumor area $^{\mathrm{a}}$ & & 0.009 & & N.S. & & N.S. & & 0.01 & & N.S. \\
\hline $\begin{array}{l}\text { Number of lymph node } \\
\text { metastasis }^{\mathrm{a}}\end{array}$ & & N.S. & & N.S. & & N.S. & & N.S. & & N.S. \\
\hline
\end{tabular}

aMann-Whitney's U tests were used. In clinical backgrounds, there were no significant differences between each of the two groups. The aFGF positive group had a larger tumor area than the aFGF negative group $(\mathrm{p}=0.009)$. The aFGF and FGFR-1 positive group had a larger tumor area than the negative group $(\mathrm{p}=0.01)$.

Table II. Correlations between ligands and receptors.

\begin{tabular}{|c|c|c|c|c|c|c|}
\hline \multirow{2}{*}{$\begin{array}{l}\text { Ligand/ } \\
\text { receptor }\end{array}$} & \multicolumn{3}{|c|}{$\mathrm{aFGF}$} & \multicolumn{3}{|c|}{ bFGF } \\
\hline & + & - & Total & + & - & Total \\
\hline \multicolumn{7}{|l|}{ FGFR-1 } \\
\hline+ & 39 & 8 & 47 & 30 & 17 & 47 \\
\hline- & 8 & 24 & 32 & 13 & 19 & 32 \\
\hline Total & 47 & 32 & 79 & 43 & 36 & 79 \\
\hline p-value & \multicolumn{3}{|c|}{$<0.0001$} & \multicolumn{3}{|c|}{0.04} \\
\hline
\end{tabular}

There were positive correlations between expression of aFGF and FGFR-1 $(\mathrm{p}<0.0001)$, and between $\mathrm{bFGF}$ and FGFR-1 $(\mathrm{p}=0.04)$.

FGFR-1 $(\mathrm{p}<0.0001)$, and between the expression of bFGF and that of FGFR-1 $(\mathrm{p}=0.04)$.

Distribution of the expression of aFGF and that of FGFR-1, and the expression of bFGF and that of FGFR-1 were analyzed (Table III). aFGF and FGFR-1, in particular, showed both strong expression and weak expression $(p<0.0001)$. There was a positive correlation between the expression of bFGF and that of FGFR-1 ( $\mathrm{p}=0.02)$.

Cumulative Kaplan-Meier survival curves for patients with aFGF-positive and aFGF-negative tumors, FGFR-1positive and FGFR-1-negative tumors, and aFGF- and FGFR-1-positive and aFGF- and FGFR-1-negative tumors were calculated (Fig. 2). The survival rate in the aFGF- and FGFR-1-positive group was significantly shorter than that in the aFGF- and FGFR-1-negative group ( $\mathrm{p}=0.04)$, and the rate in the aFGF-positive group tended to be shorter than in the
aFGF-negative group $(\mathrm{p}=0.06)$. The survival rates were not significantly different between the bFGF-positive group and the bFGF-negative group $(\mathrm{p}=0.60)$, between the FGFR-1positive group and the FGFR-1-negative group $(\mathrm{p}=0.11)$, and between the bFGF- and FGFR-1-positive group and the bFGF- and FGFR-1-negative group $(\mathrm{p}=0.43)$.

The prognostic value of co-expression of aFGF and FGFR1 and the MVD in the patients with esophageal squamous cell carcinoma was compared with that of the other clinicopathological predictive factors, such as tumor depth, tumor area and lymph node metastasis. The effects of variables associated with the prognosis were assessed by multivariate analysis using Cox's proportional hazards model, and the results of the multivariate analysis showed that the hazards ratio of the co-expression of both aFGF and FGFR-1 was the second highest, second only to lymph node metastasis, and that for the MVD was the fourth highest (Table IV).

\section{Discussion}

In this study, we clarified that there is a strong positive correlation between the expression of aFGF and FGFR-1 in esophageal squamous cell carcinoma. Co-expression of aFGF and FGFR-1 may be associated with the regulation of cell proliferation in an autocrine manner, and thereby contribute to poor prognosis. Consistent with this notion, our analysis results also indicated that co-expression of aFGF and FGFR-1 was associated with a poor prognosis in patients with esophageal squamous cell carcinoma. Numerous studies have reported correlations between prognosis and the expression status of aFGF and bFGF in a variety of cancer tissues: bFGF expression was associated with a shorter survival in cases of pancreatic ductal carcinoma (25), and 
Table III. Distribution of expression of aFGF and FGFR-1 and expression of bFGF and FGFR-1.

\begin{tabular}{|c|c|c|c|c|c|c|c|c|}
\hline & \multicolumn{4}{|c|}{ aFGF stained } & \multicolumn{4}{|c|}{ bFGF stained } \\
\hline & $<30 \%$ & $\geq 30 \%,<80 \%$ & $\geq 80 \%$ & Total & $<30 \%$ & $\geq 30 \%,<80 \%$ & $\geq 80 \%$ & Total \\
\hline \multicolumn{9}{|l|}{ FGFR-1 stained } \\
\hline$<30 \%$ & 24 & 3 & 5 & 32 & 10 & 9 & 13 & 32 \\
\hline$\geq 30 \%,<80 \%$ & 4 & 6 & 4 & 14 & 2 & 6 & 6 & 14 \\
\hline$\geq 80 \%$ & 4 & 6 & 23 & 33 & 4 & 5 & 24 & 33 \\
\hline Total & 32 & 15 & 32 & 79 & 16 & 20 & 43 & 79 \\
\hline p-value & & $<0.0001$ & & & & & 0.02 & \\
\hline
\end{tabular}

aFGF and FGFR-1 distributed to both strong expression or both weak expression.

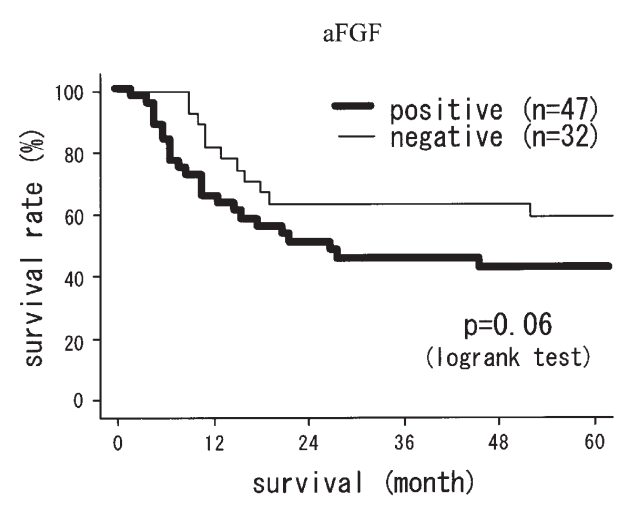

FGFR-1

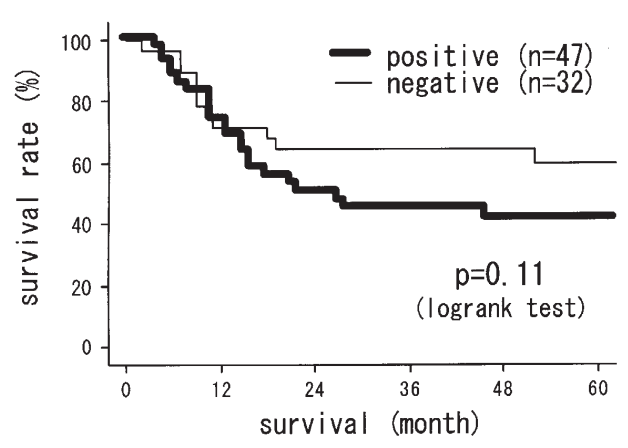

$\mathrm{aFGF}+\mathrm{FGFR}-1$

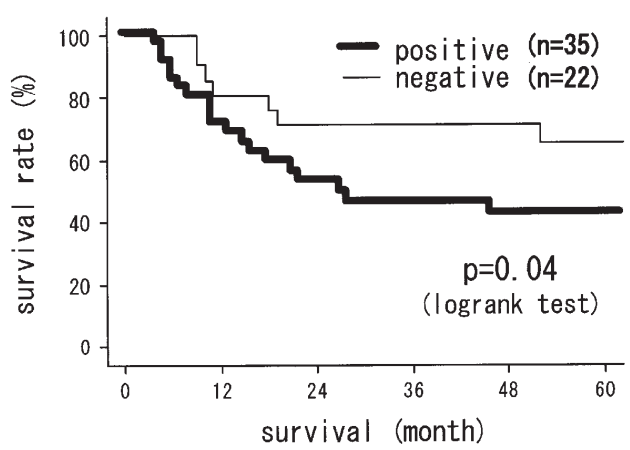

Figure 2. Kaplan-Meier survival curves. Survival was not significantly different between aFGF-positive and -negative groups $(\mathrm{p}=0.06)$, and between FGFR-1-positive and -negative groups $(\mathrm{p}=0.11)$. However, survival was significantly poorer in patients with both aFGF- and FGFR-1-positive tumors than both aFGF- and FGFR-1-negative tumors $(\mathrm{p}=0.04)$.
Table IV. Multivariate analysis using Cox's proportional hazards model.

\begin{tabular}{lcc}
\hline Factors & Hazards ratio & p-value \\
\hline pN (0 or 1) & 4.87 & 0.02 \\
$\begin{array}{l}\text { aFGF+FGFR-1 } \\
\text { (positive or negative) }\end{array}$ & 2.49 & 0.14 \\
pT (1,2 or 3) & 2.19 & 0.15 \\
MVD (count $\left./ \mathrm{mm}^{2}\right)$ & 1.01 & 0.40 \\
Tumor area $\left(\mathrm{mm}^{2}\right)$ & 1.00 & 0.64 \\
\hline
\end{tabular}

The results showed that co-expression ofaFGF and FGFR-1 had the second highest hazard ratio after the lymph node metastasis factor, and MVD had the fourth highest hazard ratio.

longer survival in cases of primary breast cancer (26), and aFGF expression was associated with an equivalent survival in cases of hepatocellular carcinoma (22).

Univariate analysis in our study showed that while the expression of aFGF, bFGF or FGFR-1 alone did not contribute to poor prognosis, co-expression of aFGF and FGFR-1 was associated with poor prognosis. Multivariate analysis showed that the hazard ratio for co-expression of aFGF and FGFR-1 was the second highest, second only to that for lymph node metastasis. While the $\mathrm{pN}$ factor has been reported to be the most useful predictor of the outcome in cases of esophageal squamous cell carcinoma. (2-3), our study showed that coexpression of aFGF and FGFR-1 was the second important predictor of a poor prognosis in cases of esophageal squamous cell carcinoma, independent of the $\mathrm{pT}$ factor, $\mathrm{pN}$ factor and the MVD. These findings suggest that co-expression of aFGF and FGFR-1 may promote cancer cell proliferation in esophageal cancer in an angiogenesis-independent autocrine manner.

On the other hand, while a positive correlation was noted between the expression of bFGF and FGFR-1 in our cases of esophageal squamous cell carcinoma, co-expression of bFGF and FGFR-1 was not associated with a poor prognosis. 
This could be explained by the poorer affinity of bFGF, as compared to that of aFGF, for FGFR-1 (27); other mechanisms inhibiting tumor growth under these circumstances may also be operative. Further investigation is required to characterize these associations.

Some studies which examined the expression of aFGF, bFGF and FGFR-1 by immunohistochemical staining and revealed correlations between ligand and receptor expression, suggest the existence of an autocrine regulatory mechanism for cancer proliferation $(19,21)$. The relationship between the production of angiogenic factor and tumor growth represents one of the most important aspects in the study of carcinogenesis (28). aFGF and bFGF are unique as, in addition to being angiogenic factors, they are also epithelial, mesodermal and neuroectodermal mitogens (24). A number of studies have shown that alterations in the expression of FGF may contribute to growth deregulation in neoplastic cells (29-32).

Numerous in vitro studies have suggested the existence of an autocrine regulatory mechanism for cancer growth: the role of aFGF and bFGF in tumor development is supported by observations that cells transfected with the aFGF or bFGF gene show increased autocrinally promoted growth in monolayer cultures and soft agar $(33,34)$. Studies employing neutralizing antibodies and anti-sense oligonucleotides which can attenuate FGF activity indicate that endogeneous aFGF and bFGF may promote neoplastic cell growth in an autocrine manner $(35,36)$. HSY human salivary-gland adenocarcinoma cells produce and utilize endogeneous aFGF and bFGF for autocrine growth via an extracellular mode of action (37). However, to the best of our knowledge, there are no published studies on the expression of aFGF, bFGF and FGFR-1 in esophageal squamous cell carcinoma cell lines. To validate our hypothesis, therefore, we considered it necessary to examine the correlations between the expression of aFGF and FGFR-1 and cancer cell proliferation.

To explain why the co-expression of aFGF and FGFR-1 in our cases of esophageal carcinoma showed no correlations with the $\mathrm{pT}$ or $\mathrm{pN}$ status but was associated with a poor prognosis, we considered that the pathological stage (pT, pN) of resected esophageal squamous cell carcinoma did not reflect the rate of cancer progression. After resection, survival directly depends on the rate of development proliferation of the residual cancer cells. If rapid proliferation of the residual cancer cells after resection in cases of esophageal cancer was promoted in an autocrine manner, it could reasonably be surmised that survival would depend not on the pathological stage, but on the expression status of aFGF and FGFR-1.s

\section{Acknowledgements}

We thank Y Nakamura for their expert technical assistance.

\section{References}

1. Sobin LH and Fleming ID: TNM Classification of Malignant Tumors, fifth edition. Union Internationale Contre le Cancer and the American Joint Committee on Cancer. TNM Prognostic Factors Project, International Union Against Cancer, Washington DC, 1997.

2. Kato H, Tachimori Y, Watanabe H, Iizuka T, Terui S, Itabashi M and Hirota T: Lymph node metastasis in thoracic esophageal carcinoma. J Surg Oncol 48: 106-111, 1991.
3. Kato H, Tachimori Y, Watanabe $\mathrm{H}$ and lizuka T: Evaluation of the new TNM classification for thoracic esophageal tumors. Int J Cancer 53: 220-223, 1993.

4. Fahn HJ, Wang LS, Huang BS, Huang MH and Chien KY: Tumor recurrence in long-term survivors after treatment of carcinoma of the esophagus. Ann Thorac Surg 57: 677-681, 1994.

5. Shih CH, Ozawa S, Ando N, Ueda M and Kitajima M: Vascular endothelial growth factor expression predicts outcome and lymph node metastasis in squamous cell carcinoma of the esophagus. Clin Cancer Res 6: 1161-1168, 2000.

6. Folkman J: What is the evidence that tumors are angiogenesis dependent? J Natl Cancer Inst 82: 4-6, 1990.

7. Liotta LA, Kleinerman J and Saidel GM: The significance of heterogeneous tumor cell clumps in the metastatic process. Cancer Res 36: 889-894, 1976.

8. Nagy JA, Brown LF, Senger DR, Lanir N, Van de Water L, Dvorak AM and Dvorak HF: Pathogenesis of tumor stroma generation: a critical role for leaky blood vessels and fibrin deposition. Biochim Biophys Acta 948: 305-326, 1989.

9. Folkman J: Tumor angiogenesis: therapeutic implications. N Engl J Med 285: 1182-1186, 1971.

10. Folkman J and Klagsbum M: Angiogenic factors. Science 235: 442-447, 1987.

11. Basilico C and Moscatelli D: The FGF family of growth factors and oncogenes. Adv Cancer Res 59: 115-165, 1992.

12. Yamasaki M, Miyake A, Tagashira S and Itoh N: Structure and expression of the rat mRNA encoding a novel member of the fibroblast growth factor family. J Biol Chem 271: 15918-15921, 1996.

13. Smallwood PM, Munoz-Sanjuan I, Tong P, Macke JP, Hendry SHC, Gilbert DJ, Copeland NG, Jenkins NA and Nathan J: Fibroblast growth factor (FGF) homologous factors: new members of the FGF family implicated in nervous system development. Proc Natl Acad Sci USA 93: 9850-9857, 1996.

14. Baird A and Bohlen P: Fibroblast growth factors. In: Peptide Growth Factors and their Receptors. Sporn MB and Roberts AB (eds.). Springer Verlag, Berlin, pp369-403, 1990.

15. Peyrat JP, Bonneterre J, Hondermarck H, Hecquet B, Adenis A, Louchez MM, Lefebvre J, Boilly B and Demaille A: Basic fibroblast growth factor (bFGF): mitogenic activity and binding sites in human breast cancer. J Steroid Biochem Mol Biol 43: 87-94, 1992.

16. Blanckaert VD, Schelling ME, Elstad CA and Meadows GG: Differential growth factor production, secretion and response by high and low metastatic variants of B16BL6 melanoma. Cancer Res 53: 4075-4081, 1993

17. Johnson D and Williams L: Structural and functional diversity in the FGF receptor multigene family. Adv Cancer Res 60: 1-41, 1993.

18. Luqmani YA, Graham M and Coombes RC: Expression of basic fibroblast growth factor, FGFR1 and FGFR2 in normal tissues. Br J Cancer 66: 273-280, 1992.

19. Yoshimura N, Sano H, Hashiramoto A, Yamada R, Nakajima H, Kondo $\mathrm{M}$ and Oka T: The expression and localization of fibroblast growth factor-1 (FGF-1) and FGF receptor-1 (FGFR-1) in human breast cancer. Clin Immunol Immunopathol 89: 28-34, 1998.

20. Yamaguchi F, Saya H, Bruner JM and Morrison RS: Differential expression of two fibroblast growth factor-receptor genes is associated with malignant progression in human astrocytomas. Proc Natl Acad Sci USA 91: 484-488, 1994.

21. Kin M, Sata M, Ueno T, Torimura T, Inuzuka S, Tsuji R, Sujaku K, Sakamoto M, Sugawara H, Tamaki S and Tanikawa K: Basic fibroblast growth factor regulates proliferation and motility of human hepatoma cells by an autocrine mechanism. J Hepatol 27: 677-687, 1997

22. Chow NH, Cheng KS, Lin PW, Chan SH, Su WC, Sun YN and Lin XZ: Expression of fibroblast growth factor-1 and fibroblast growth factor-2 in normal liver and hepatocellular carcinoma. Dig Dis Sci 43: 2261-2266, 1998.

23. Yamanaka Y, Friess H, Bunchler M, Beger HG, Uchida E, Onda M, Kobrin MS and Korc M: Overexpression of acidic and basic fibroblast growth factors in human pancreatic cancer correlates with advanced tumor stage. Cancer Res 53: 5289-5296, 1993.

24. Burgess WH and Mactag T: The heparin-binding (fibroblast) growth factor family of proteins. Ann Rev Biochem 58: 575$606,1989$. 
25. Kuwahara K, Sakaki T, Kuwada Y, Murakami M, Yamasaki S and Chayama K: Expression of angiogenic factors in pancreatic ductal carcinoma: a correlative study with clinicopathologic parameters and patient survival. Pancreas 26: 344-349, 2003.

26. Linderholm BK, Lindh B, Beckman L, Erlanson M, Edin K, Travelin B, Bergh J, Grankvist K and Henriksson R: Prognostic correlation of basic fibroblast growth factor and vascular endothelial growth factor in 1307 primary breast cancers. Clin Breast Cancer 4: 340-347, 2003.

27. Beer HD, Vindevoghel L, Gait MJ, Revest JM, Duan DR, Mason I, Dickson C and Werner S: Fibroblast growth factor (FGF) receptor 1-IIIb is a naturally occurring functional receptor for FGFs that is preferentially expressed in the skin and the brain. J Biol Chem 275: 16091-16097, 2000.

28. Bosari J, Lee AKC, De Lellis RA, Wiley BD, Heatley GJ and Silverman ML: Microvessel quantitation and prognosis in invasive breast carcinoma. Hum Pathol 23: 755-761, 1992.

29. Stefanik DF, Rizkalla LR, Soi A, Goldblatt SA and Rizkalla WM: Acidic and basic fibroblast growth factors are present in glioblastoma multiforme. Cancer Res 51: 5760-5765, 1991.

30. Tanimoto H, Yoshida K, Yokozaki H, Yasui W, Nakayama H, Ito $\mathrm{H}$, Ohama $\mathrm{K}$ and Tahara $\mathrm{E}$ : Expression of basic fibroblast growth factor in human gastric carcinomas. Virchows Arch B Cell Pathol 61: 263-267, 1991.

31. Eguchi J, Nomata K, Kanda S and Igawa T: Gene expression and immunohistochemical localization of basic fibroblast growth factor in renal cell carcinoma. Biochem Biophys Res Commun 183: 937-944, 1992.
32. Myoken Y, Myoken Y, Okamoto T, Sato JD and Takada K: Immunohistochemical localization of fibroblast growth factor-1 (FGF-1) and FGF-2 in oral squamous cell carcinoma (SCC). J Oral Pathol Med 23: 451-456, 1994.

33. Jaye M, Lyall RM, Mudo R, Schlessinger J and Sarver N: Expression of acidic fibroblast growth factor cDNA confers growth advantage and tumorigenesis to Swiss $3 \mathrm{~T} 3$ cells. EMBO J 7: 963-969, 1988.

34. Sasada R, Kurokawa T, Iwane $M$ and Igarashi $K$ : Transformation of mouse BALB/c 3T3 cells with human basic fibroblast growth factor cDNA. Mol Cell Biol 8: 588-594, 1988.

35. Morrison RS: Suppression of basic fibroblast growth factor expression by antisense oligodeoxynucleotides inhibits the growth of transformed human astrocytes. J Biol Chem 266: 728-734, 1991.

36. Myoken Y, Myoken Y, Okamoto T, Kan M, Sato JD and Takada K: Release of fibroblast growth factor-1 by human squamous cell carcinoma correlates with autocrine cell growth. In Vitro Cell Dev Biol 30: 790-795, 1994.

37. Myoken Y, Myoken Y, Okamoto T, Kan M, McKeehan WL, Sato JD and Takada K: Expression of fibroblast growth factor-1 (FGF-1), FGF-2 and FGF receptor-1 in a human salivary-gland adenocarcinoma cell line: evidence of autocrine growth. Int $\mathbf{J}$ Cancer 65: 650-657, 1996. 